\section{Keine Süssgetränke}

und Süssigkeiten

mehr an Schulkiosken

An Schulen und Horten in der Stadt Zürich gibt es künftig nur noch gesunde und zahnschonende Ernährung. Neue Ernährungsrichtlinien der Schulgesundheitsdienste sind von der Schulpräsidentenkonferenz für verbindlich erklärt worden. In Pausenkiosken werden bis Ende 2009 Süssgetränke, Süssigkeiten und fettreiche Snacks durch gesündere Angebote ersetzt.

(SDA)

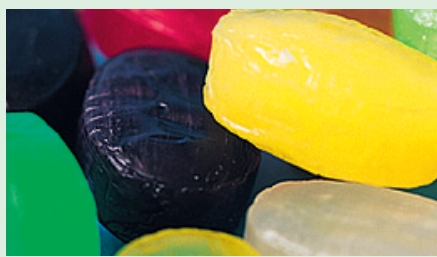

Brücken bauen - Die Welten der Kinder miteinander verbinden

Um mit Eltern - unabhängig von ihrer Herkunftskultur, ihrer Bildungsnähe und ihren Kenntnissen der lokalen Sprache - über pädagogische Themen zu kommunizieren, braucht es Informationsmittel, die einen unmittelbaren Zugang erlauben. Mit «Brücken bauen - Die Welten der Kinder miteinander verbinden» liegt nun ein interkulturell konzipierter Film über ein zentrales pädagogisches Thema vor. Es geht darin um Brücken und Verbindungen zwischen den Welten, in denen die Kinder heranwachsen. Er zeigt alltagsnahe Möglichkeiten auf, wie Eltern für ihre Kinder von der frühen Kindheit an bis zur Adoleszenz solche Brücken bauen können. Der Film liegt in insgesamt 14 Sprachversionen vor.

(Schulverlag blmv $A G)$

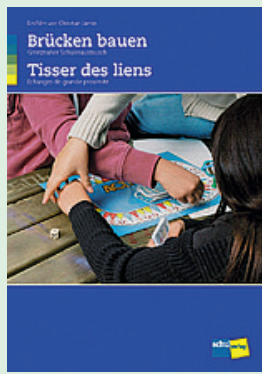

\section{Die Qualität der medizinischen Hochschullehre verbessern}

Um einen neuen Schwerpunkt in Medizindidaktik und Ausbildung am Krankenbett zu setzen, hat die Medizinische Fakultät der Universität Zürich als Erste in der Schweiz den Titel der Klinischen Dozentin bzw. des Klinischen Dozenten eingeführt. Was in anderen Ländern unter dem Titel des «clinical professorship» etabliert ist, wurde 2004 in der Schweiz erstmals als Titel lanciert und ausgeschrieben; seither wurden 27 Per- sonen zur Klinischen Dozentin bzw. zum Klinischen Dozenten ernannt. Nun haben sich die Klinischen Dozentinnen und Dozenten zu einer Vereinigung zusammengeschlossen, um ihrem Anliegen, die Qualität der medizinischen Hochschullehre zu verbessern, mehr Nachdruck zu verleihen.

(www.klinische-dozenten.ch)

\section{Journée de la recherche: le FNS en visite au Tessin}

Le 14 mai 2009, dans le cadre de la Journée de la recherche, le Fonds national suisse de la recherche scientifique présentera ses instruments d'encouragement de la recherche à l'Università della Svizzera italiana (USI) à Lugano par le biais de stands d'information et de conférences. Les participants auront par ailleurs l'occasion de poser des questions individuelles et, au cours d'ateliers, d'obtenir des conseils sur la manière de formuler une requête qui aboutisse. Les chercheurs provenant de toutes les universités seront les bienvenus.

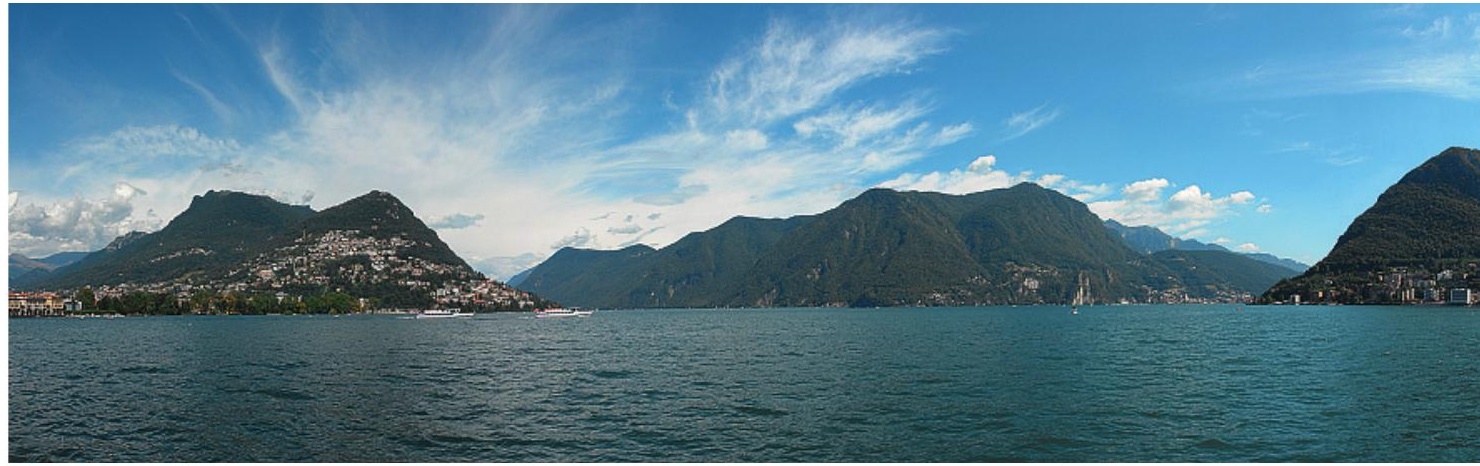

Lago-di-Lugano-Panorama.

\section{Eliminer des obstacles en relançant la conjoncture}

L'association suisse pour personnes avec handicap Procap exige que l'élimination des barrières architecturales soit considérée comme une tâche urgente devant être intégrée dans les programmes conjoncturels présents et futurs. C'est pourquoi Procap a préparé un document contenant des propositions concrètes, qu'il a envoyé aux partis représentés au Palais fédéral, à divers parlementaires choisis ainsi qu'au Secrétariat d'Etat à l'économie (seco). Une partie de ces mesures peut être rapidement mise en œuvre.

(www.procap.ch)

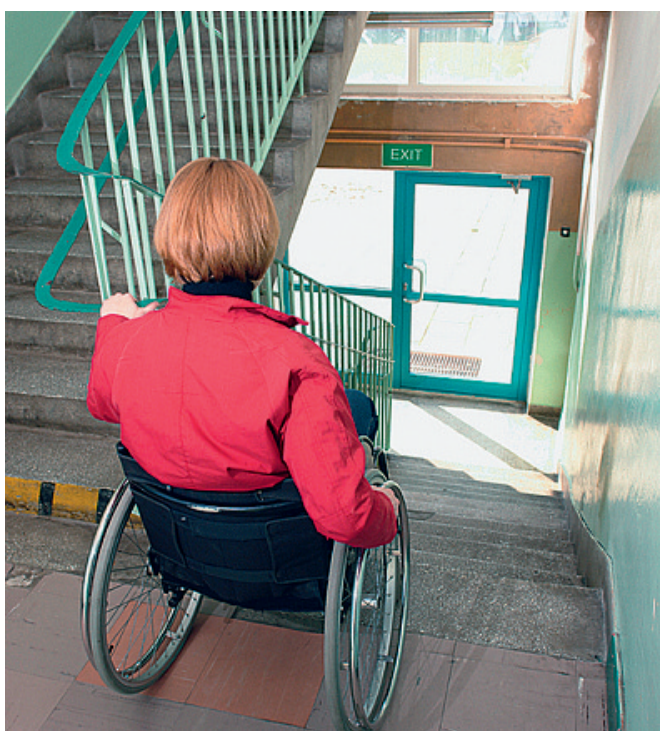

